\title{
Gas Turbine Engine Anomaly Detection Through Computer Simulation Technique of Statistical Correlation
}

\author{
E. A. Ogbonnaya ${ }^{a}$, H. U. Ugwu ${ }^{a}$, K. Theophilus-Johnson ${ }^{b}$ \\ .$^{a}$ Department of Mechanical Engineering, Michael Okpara University of Agriculture, Umudike-Umuahia, Nigeria \\ ${ }^{b}$ Department of Marine Engineering, Faculty of Engineering, Rivers State University of Science and Technology, P.M.B. \\ 5080, Port Harcourt, Nigeria
}

\begin{abstract}
Inefficiencies of compressors and turbines resulting from insufficient pressure ratio at successive blade stages in gas turbines often lead to flow reversals. A step to statistically correlate boost pressure and vibration velocity amplitude to avoid such flow reversals therefore led to the execution of this research. A computer simulation technique was used to actualize this purpose with the operational data obtained from Delta IV unit of Ughelli power station GT 18 using VC++ programming language. Results obtained show that maximum vibration manifests on each of the bearings at a pressure ratio of 9.47 for all cases considered. These results further show a linear relationship between the data using statistical z- test.
\end{abstract}

Keywords: Computer simulation; Statistical correlation; Gas turbine; Anomaly detection; Vibration amplitude; Pressure Ratio.

\section{Introduction}

The marine gas turbine (GT) in many respects is the most significant means of creating mechanical power among the other various means. Although GTs obtain their power by utilizing the energy of burnt gases and air which are at high temperature and pressure while expanding through several rings of fixed and rotating blades [1]. GTs are increasingly being used all over the world for various applications, some of which include power generation, aero-propulsion, propulsion of ships, operation of pumps and compressors [2]. In Nigeria, GTs are used mainly for electricity generation, base-load operations, standby power generating plants including aircraft and ship propulsion. Most oil companies like Agip, Chevron, Elf and Shell also use gas turbines for electricity generation and other purposes [3].

In this paper, an approach is presented for estimating the risk reduction associated with vibration amplitude and boost pressure. $\mathrm{VC}++$ programming language was used to determine the statistical correlation coefficient between boost pressure and vibration amplitude.

\subsection{Factors affecting performance}

GTs operates efficiently if the energy conversion process is operated at the following thermodynamically favorable conditions:
1. High pressure and temperature at the turbine inlet,

2. Minimal losses during compression and expansion.

While conversion losses can be minimized through optimal aerodynamic design of the compressor and turbine, the high pressure ratios of $20: 1$ or greater and turbine inlet temperatures of $1371.11^{\circ} \mathrm{C}$ and above are desirable for increased efficiency. Effectively, to achieve the thermal efficiencies delivered by modern GTs, they must work at process conditions that push the mechanical and thermal stress of the materials used in the machine's gas path components to their limits [4].

Ambient conditions affect a GT at both the compressor inlet and the turbine outlet. At the compressor inlet, the higher the temperature and the lower the pressure, the less the mass flow that can be generated through the turbine. Humidity also plays a role. Higher specific humidity increases the specific volume of the inlet airflow, so that the mass flow through the turbine is reduced resulting in less power output and increased heat rate. At the turbine outlet, ambient conditions also play a role. The higher the pressure, the less energy that can be converted to shaft power. 


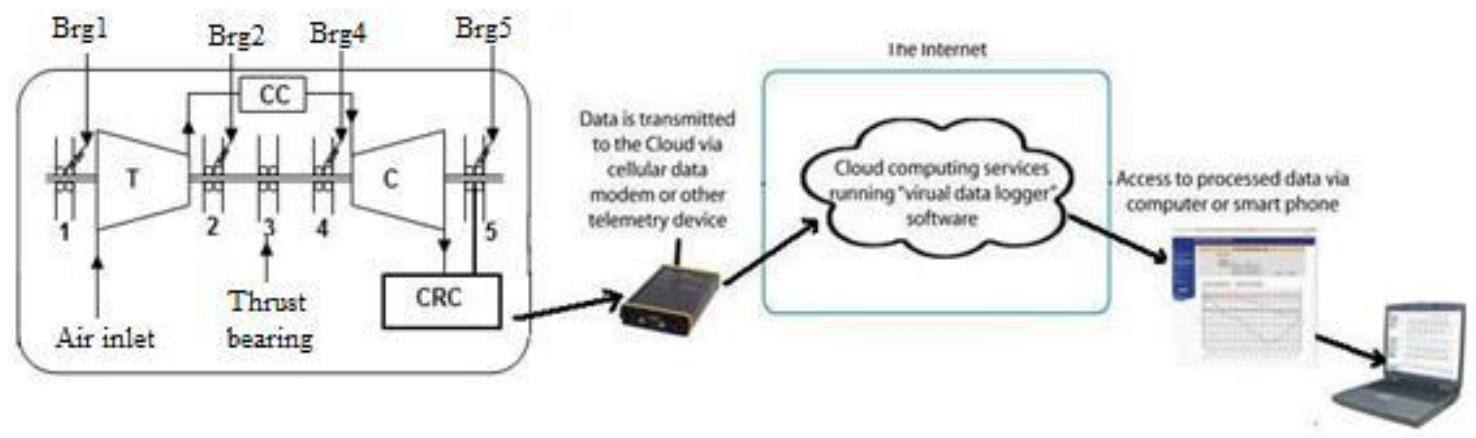

Fig.1 Experimental setup for data collection

\subsection{Gas turbine vibration monitoring technique} Early discovery of a GT malfunctions gives equipment owner and operators an opportunity to prevent sudden failure. Vibration monitoring can quickly determine that a problem has occurred and the machine is in distress. For example, GTs generally trip offline due to high vibration amplitude from an event such as blade loss. Although blade failure is caused by another mechanism, adequate vibration monitoring and protection systems allow the operator to react to the failure, shut down the engine in a controlled manner and make necessary repairs [6].

\subsection{Laplace correction for missing data}

Test data sets do not usually contain a complete representation of the confusion matrix. The low probability of the off diagonal elements occuring requries a very large data set to accurately capture the true distribuiton of the complete population. Applying a Laplace correction to the mean cost matrix compensates for the missing data and improves the confidence interval on the resulting cost value[7]. In addition to improving the confidence interval on the average matrix, a Laplace correction can be applied to improve the confidence intervals on the entries in the confusion matrix, including zero value entries that otherwise would not have a confidence interval [8].

The Laplace correction matrix is produced with the equation below:

$$
L=\frac{\mathrm{Pn}+\lambda}{\mathrm{n}+\mathrm{F}^{2} \lambda}
$$

Also, according to [9], without the knowledge of the relative frequency with which two or more phenomena occurs, it would be impossible to predict accurately future events, i.e. where correlation becomes involved [10].

\subsection{Correlation in GT engine anormaly detection} Correlation is one of the most common and useful statistical techniques that can be used to link two very important variables. Also, correlation is a single number that describes the degree of relationship between two variables. Hence, it was carried out for pressure ratio and vibration amplitude in GT engine anormaly detection. Linear correlation coefficient was thus the particular aspect of correlation used in this work [10].

\subsection{Correlation between Pressure Ratio and Vibration Amplitude Measurement}

To calculate a linear correlation coefficient, a random sample of $\mathrm{n}$ pairs of measurements $(\mathrm{x}, \mathrm{y})$ is first chosen, by constructing a scatter diagram for the $(\mathrm{x}, \mathrm{y})$ value (see fig. 2a). If the points follow closely a straight line of positive slope, then there is a case of high positive correlation between the two variables. On the other hand, if the points closely follow a straight line of negative slope, we have a high negative correlation between the two variables as in fig. 3(b). If the points follow a strictly random pattern as in fig. 3(c), then there is zero correlation and it is concluded that there is no relationship between $\mathrm{x}$ and $\mathrm{y}$. Zero correlation is also indicated when the pattern shown in fig 3(d) is obtained[11]. 

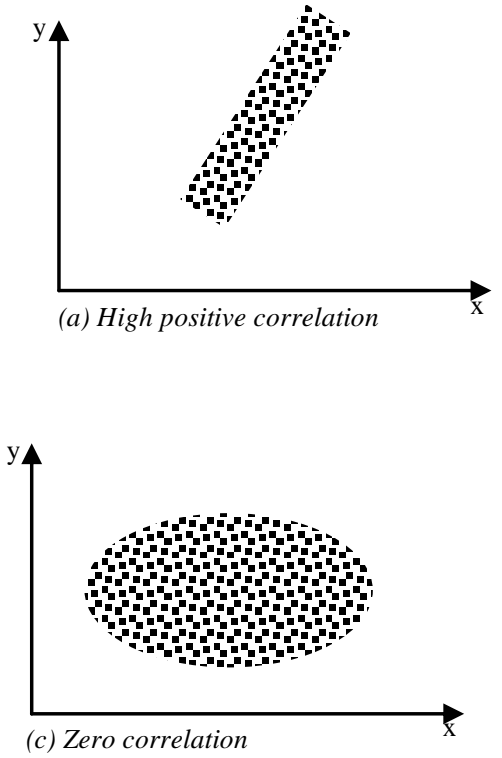
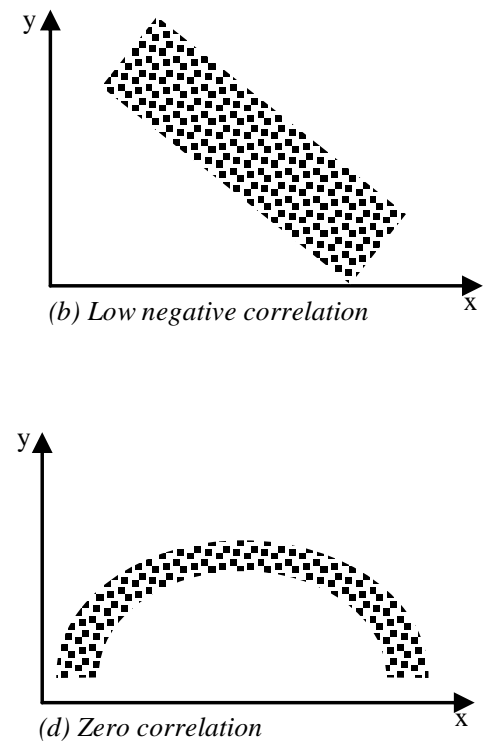

Fig.2 Scatter diagrams showing various degrees of correlation

It is important to remember that the correlation coefficient between two variables is a measure of their linear relationship and a value of $\rho=0$ implies a lack of linearity and not a lack of association. Hence, if a strong quadratic relationship exists between $\mathrm{x}$ and $y$ as indicated in fig. 3(d), a zero correlation to indicate a nonlinear relationship would still be obtained. This is the most commonly used measure of linear correlation between two variables and is called the Pearson product-moment correlation coefficient, or the sample correlation coefficient. The above approach was greatly used in this research.

Using equation (2) to obtain the correlation coefficient through $\mathrm{VC}++$ programming language, it is assumed that a suitable correlation between pressure ratio (y) and vibration amplitude $\left(x_{i}\right)$ has been obtained either by least-square analysis or graphical curve fitting. To know how good this is, the parameter which conveys this information is the correlation coefficient $r$ defined by

$$
r=\left[1-\frac{\sigma^{2} y, x}{\sigma_{y}{ }^{2}}\right]^{1 / 2}
$$

where $\sigma_{y}$ is the standard deviation of y given as:

$$
\sigma_{y}=\left[\frac{\sum_{i=1}^{n}\left(y_{i}-y_{m}\right)^{2}}{n-1}\right]^{1 / 2}
$$

and

$$
\sigma_{y_{, x}}=\left[\frac{\sum_{i=1}^{n}\left(y_{i}-y_{i c}\right)^{2}}{n-2}\right]^{1 / 2}
$$

The $y_{i}$ are the actual values of $y$, and the $y_{i c}$ are the values computed from the correlation equation for the same value of $x$. It may be noted that many calculators have built-in routines which compute the correlation coefficient as well as other statistical functions. In addition there are many computer software packages which accomplish these calculations, such as, visual $\mathrm{C}++$, Matlab etc. In order to obtain the correlation coefficient, we seek an equation of the form.

$$
y_{i c}=a x+b
$$

which is called the correlating equation

$$
\text { where } a=\frac{n \sum x_{i} y_{i}-\left(\sum x_{i}\right)\left(\sum y_{i}\right)}{n \sum x_{i}^{2}-\left(\sum x_{i}\right)^{2}}
$$

Designating the computed value of $\mathrm{y}$ as $\mathrm{y}_{\mathrm{ic}}$ and

$$
b=\frac{\left(\sum y_{i}\right)\left(\sum x_{i}^{2}\right)-\left(\sum x_{i} y_{i}\right)\left(\sum x_{i}\right)}{\left(\sum x_{i}^{2}\right)-\left(\sum x_{i}\right)^{2}}
$$

The correlation will be used to advantage by indicating if the correlation is weak (i.e. if $r$ is close to zero) or we can also say that a very good linear 
relationship exist if the values of $\mathrm{P}_{\mathrm{r}}(\mathrm{Y})$ is accounted for by a linear relationship with vibration amplitude (x).

A multiple variable mathematical model of the GT operating parameters [5] was integrated and used to actualize the whole process. This program has the typical result obtainable when the GT is in operation[12].

\section{Results and discussion}

The hypothesis testing of the test engine is given as follows:

$$
Z=\frac{\sqrt{n-3}}{2} \ln \left[\frac{(1+r)}{(1-r)} \frac{\left(1-\rho_{o}\right)}{\left(1+\rho_{o}\right)}\right]
$$

Correlation coefficient (r) for bearing $1=0.997171$

Null Hypothesis $H_{0}: \rho_{0}=0$

Research Hypothesis $H_{1}: \rho_{1} \neq 0$

Statistical Test: Since $\mathrm{n}$ is large, Z-test is appropriate Level of Significance $\alpha=0.05$ (95\% confidence level) Critical Region: $Z<-1.96$ and $Z>1.96$

Computations: Using equation (3.28)

$Z_{C 1}=\frac{\sqrt{n-3}}{2} \ln \left[\frac{(1+r)\left(1-\rho_{0}\right)}{(1-r)\left(1+\rho_{0}\right)}\right]=\frac{\sqrt{12-3}}{2} \ln \left(\frac{1.997171}{0.002829}\right)$

$=\frac{\sqrt{9}}{2} \ln (705.9636)$

$z_{C 1}=6.55$

Decision: $z_{C 1}>1.96$ Reject $\mathrm{H}_{0}$

Correlation coefficient (r) for Bearing $2=0.991471$

$Z_{C 2}=5.45$

Decision: $z_{C 2}>1.96 \quad$ Reject $\mathrm{H}_{0}$

Correlation coefficient (r) for Bearing $4=0.955811$

$Z_{C 4}=3.80$

Decision: $Z_{C 4}>1.96 \quad$ Reject $\mathrm{H}_{0}$
Correlation coefficient (r) for Bearing $5=0.987502$

$$
z_{C 5}=5.07
$$

Decision: $z_{C 5}>1.96$ Reject $\mathrm{H}_{0}$

Theoretically;

$$
r_{p}=\frac{p_{2}}{p_{1}}=\frac{p_{3}}{p_{4}}
$$

But practically for compressor,

$$
\begin{aligned}
& r_{p_{c}}=\left(\frac{T_{2}}{T_{1}}\right)^{\frac{r}{r-1}}=\left(\frac{58.3593}{30}\right)^{\frac{1.4}{1.4-1}} \\
& r_{p_{c}}=(2.0279)^{3.5} \\
& r_{p_{c}}=10.28
\end{aligned}
$$

Also for turbine,

$$
\begin{aligned}
& r_{p_{t}}=\left(\frac{T_{3}}{T_{4}}\right)^{\frac{r}{r-1}}=\left(\frac{979.343}{537}\right)^{\frac{1.4}{1.4-1}} \\
& r_{p_{t}}=(1.9012)^{3.5}=8.19 \quad \text { i.e. } \quad r_{p_{c}} \neq r_{p_{t}}
\end{aligned}
$$

(practically)

Fig 3 shows a program flow chart for correlation coefficient of the experimental data for the test engine using equation 2. A computer program code was written from fig. 3 and equation 2. From the output of the subroutine program shown in table 1 , it is observed that the pressure ratio of the compressor is not equal to the pressure ratio of the turbine and this can be accounted for by the decrease in boost pressure. The data for the program was used to produce the graphs shown in figs. 4 to 13. Readings are not taken from bearing 3 as no transducer is fitted to it. It is the thrust bearing 3. Graphs of pressure ratio versus vibration velocity amplitude of bearings 1 to 5 are plotted in the figs 4 to13.

Designing the computed value of $y$ as $y_{i c}$, the correlation coefficient will be obtained from tables 1 to $1 \mathrm{a}, 2$ to $2 \mathrm{a}$ using the least square methods. The result thus shows why excessive pressure ratio is to be avoided at the design stage of the marine GT compressors manufacture. 
IOSR Journal of Engineering

Apr. 2012, Vol. 2(4) pp: 544-554
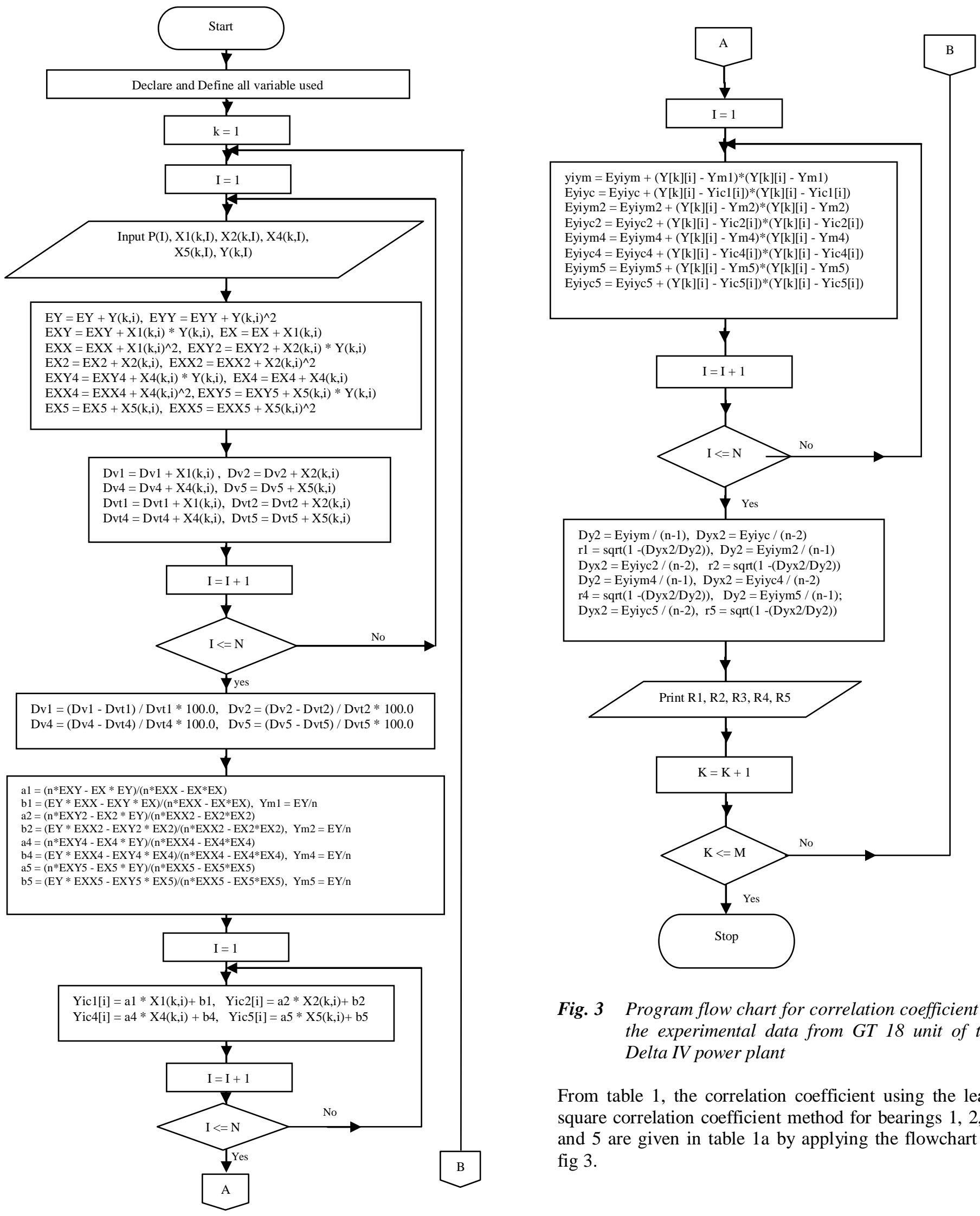

Fig. 3 Program flow chart for correlation coefficient of the experimental data from GT 18 unit of the Delta IV power plant

From table 1, the correlation coefficient using the least square correlation coefficient method for bearings 1, 2, 4 and 5 are given in table 1a by applying the flowchart in fig 3. 
Table 1: Reading taken from GT 18 unit of Delta IV power section

\begin{tabular}{lllllllll}
\hline $\begin{array}{l}\text { May } \\
\text { Time }\end{array}$ & $\begin{array}{l}\text { Load } \\
\text { Mw }\end{array}$ & $\operatorname{Brg} 1$ & $\operatorname{Brg} 2$ & $\operatorname{Brg} 4$ & $\operatorname{Brg} 5$ & Speed & $\begin{array}{l}\text { Cpd } \\
\text { pressure }\end{array}$ & $\begin{array}{l}\text { Compressor } \\
\text { Ratio } \mathrm{P}_{2} / \mathrm{P}_{1}\end{array}$ \\
\hline 0100 & 93 & 3.50 & 2.00 & 0.50 & 0.20 & 3000 & 9.6 & 9.47 \\
0200 & 93 & 3.54 & 2.10 & 0.54 & 0.21 & 3000 & 9.6 & 9.47 \\
0300 & 95 & 3.58 & 2.20 & 0.58 & 0.22 & 3090 & 9.8 & 9.67 \\
0400 & 95 & 3.62 & 2.30 & 0.62 & 0.23 & 3060 & 9.8 & 9.67 \\
0500 & 90 & 3.66 & 2.40 & 0.66 & 0.24 & 3000 & 9.4 & 9.28 \\
0600 & 40 & 3.70 & 2.50 & 0.70 & 0.25 & 3060 & 8.0 & 7.90 \\
0700 & 50 & 3.74 & 2.60 & 0.74 & 0.26 & 3060 & 8.6 & 8.49 \\
0800 & 50 & 3.78 & 2.70 & 0.78 & 0.27 & 3000 & 8.6 & 8.49 \\
0900 & 75 & 3.82 & 2.80 & 0.82 & 0.28 & 3000 & 9.2 & 9.08 \\
1000 & 76 & 3.86 & 2.90 & 0.86 & 0.29 & 3000 & 9.2 & 9.08 \\
1100 & 74 & 3.90 & 3.00 & 0.90 & 0.30 & 3000 & 9.2 & 9.08 \\
1200 & 74 & 3.94 & 3.94 & 0.94 & 0.94 & 3030 & 9.2 & 9.08 \\
& & & & & & & & $\sum y_{i}=108.8$ \\
\hline
\end{tabular}

Table 1a: The least square correlation coefficient obtained from Table 2

\begin{tabular}{lllll}
\hline $\begin{array}{l}\text { correlation } \\
\text { coefficient }\end{array}$ & $\operatorname{Brg} 1(\mathrm{~mm} / \mathrm{s})$ & $\operatorname{Brg} 2(\mathrm{~mm} / \mathrm{s})$ & $\operatorname{Brg} 4(\mathrm{~mm} / \mathrm{s})$ & $\operatorname{Brg} 5(\mathrm{~mm} / \mathrm{s})$ \\
\hline $\mathrm{r}_{1}(\%)$ & 20.11 & 25.48 & 26.18 & 18.29 \\
\hline
\end{tabular}

Also from table 2, the correlation coefficient using the least square method for bearing 1 , bearing 2 , bearing 4 and bearing 5 are given in table $3 \mathrm{a}$ while applying the flowchart in fig 3 .

Graphical analysis of pressure ratio versus vibration velocity amplitude for tables 1 , and 2 are shown and analyzed in figs 4 to 13 . These plots show that vibration signature output is sinusoidal, erratic and unpredictable. Further more, it is observed that the effect of pressure ratio against vibration amplitude on all the bearings is same.Hence care has to be taken to avoid excessive pressure ratio at GT engine design stages.

From the graphs shown in figs 4 to 13 , it is observed that an increase in pressure ratio also results to a corresponding increase in vibration velocity amplitude to some extent. However, in this case, maximum vibration occurs at a pressure ratio of about 9.47 with a corresponding vibration velocity amplitude of $3.94 \mathrm{~mm} / \mathrm{s}$, $3.10 \mathrm{~mm} / \mathrm{s}, 0.94 \mathrm{~mm} / \mathrm{s}$ and $0.31 \mathrm{~mm} / \mathrm{s}$ respectively where it is not equally advisable to run the engine. This would additionality help to avoid eccentricity, imbalance and even resonance on the engine.

Table 2: Reading taken from GT 18 unit of Delta IV power section

\begin{tabular}{lllllllll}
\hline $\begin{array}{l}\text { May } \\
\text { Time }\end{array}$ & $\begin{array}{l}\text { Load } \\
\text { Mw }\end{array}$ & Brg1 & Brg2 & $\operatorname{Brg} 4$ & $\operatorname{Brg} 5$ & Speed & $\begin{array}{l}\text { Cpd } \\
\text { program }\end{array}$ & $\begin{array}{l}\text { Compressive press } \\
\text { on Ratio } \mathrm{P}_{2} / \mathrm{P}_{1}\end{array}$ \\
\hline 0100 & 75 & 3.40 & 2.00 & 0.60 & 0.20 & 3060 & 9.0 & 8.90 \\
0200 & 75 & 3.44 & 2.04 & 0.66 & 0.21 & 3060 & 9.0 & 8.90 \\
0300 & 80 & 3.48 & 2.08 & 0.72 & 0.22 & 3060 & 9.0 & 8.90 \\
0400 & 85 & 3.52 & 2.12 & 0.78 & 0.23 & 3030 & 9.6 & 9.47 \\
0500 & 90 & 3.56 & 2.16 & 0.84 & 0.24 & 3000 & 9.3 & 9.18 \\
0600 & 80 & 3.60 & 2.20 & 0.90 & 0.25 & 3000 & 9.3 & 9.18 \\
0700 & 87 & 3.64 & 2.24 & 0.96 & 0.26 & 3030 & 9.3 & 9.18 \\
0800 & 90 & 3.68 & 2.28 & 1.02 & 0.27 & 3030 & 9.7 & 9.57 \\
0900 & 85 & 3.72 & 2.32 & 1.08 & 0.28 & 2970 & 9.7 & 9.57 \\
1000 & 75 & 3.76 & 2.36 & 1.14 & 0.29 & 3030 & 9.0 & 8.90 \\
1100 & 65 & 3.80 & 2.40 & 1.20 & 0.30 & 3060 & 9.0 & 8.90 \\
1200 & 80 & 3.84 & 2.44 & 1.26 & 0.31 & 3060 & 9.0 & 8.90 \\
& & & & & & & & $\sum y_{i}=109.55$ \\
\hline
\end{tabular}


Table 2a: The least square correlation coefficient obtained from Table 2

\begin{tabular}{lllll}
$\begin{array}{l}\text { correlation } \\
\text { coefficient }\end{array}$ & $\operatorname{Brg} 1(\mathrm{~mm} / \mathrm{s})$ & $\operatorname{Brg} 2(\mathrm{~mm} / \mathrm{s})$ & $\operatorname{Brg} 4(\mathrm{~mm} / \mathrm{s})$ & $\operatorname{Brg} 5(\mathrm{~mm} / \mathrm{s})$ \\
\hline $\mathrm{r}_{1}(\%)$ & 83.13 & 98.84 & 98.91 & 98.86 \\
\hline
\end{tabular}

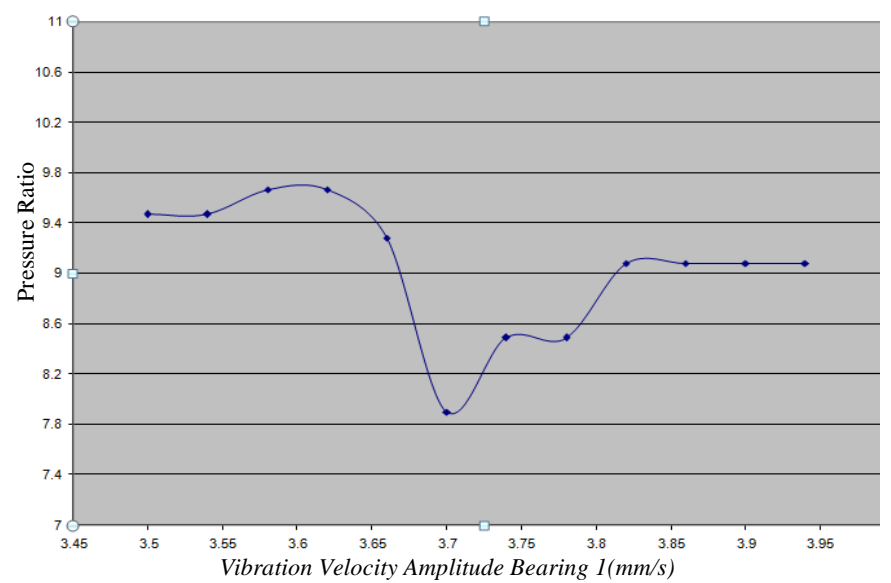

Fig.4 Pressure ratio against Vibration Velocity Amplitude Bearing 1 obtained from Equation 8

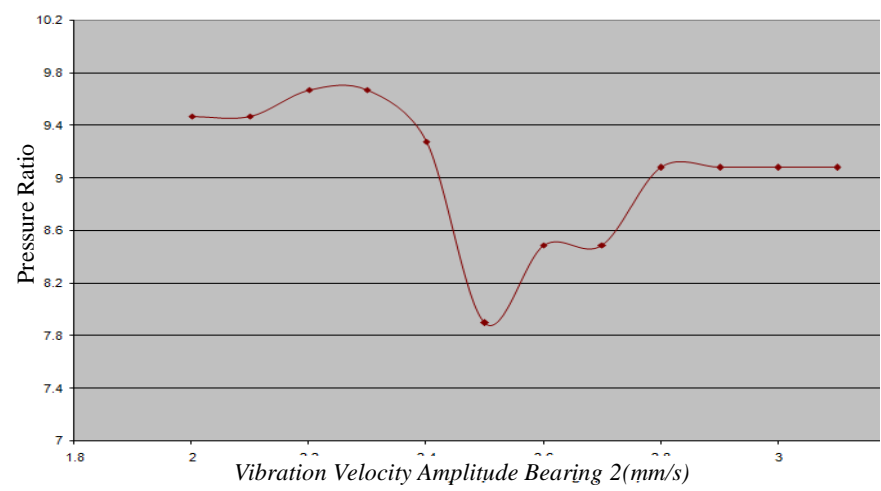

Fig.5 Pressure ratio against Vibration Velocity Amplitude Bearing 2 obtained from Equation 8

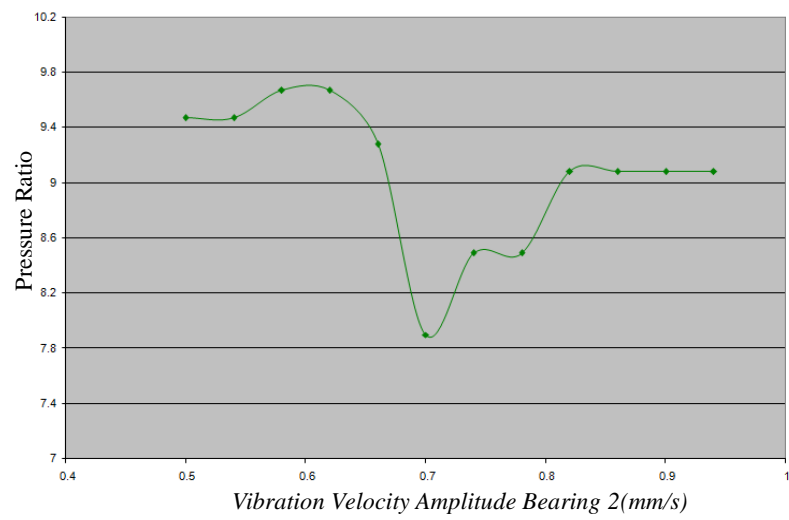

Fig.6 Pressure ratio against Vibration Velocity Amplitude Bearing 4 obtained from Equation 8

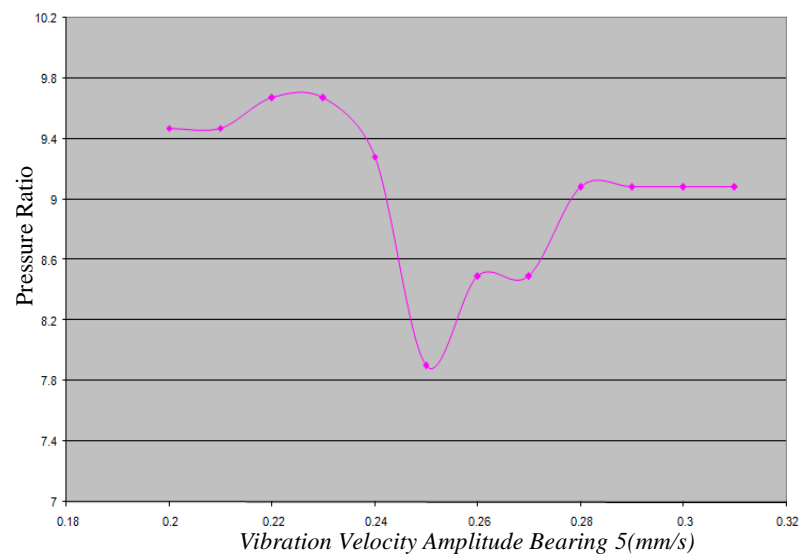

Fig.7 Pressure ratio against Vibration Velocity Amplitude Bearing 5 obtained from Equation 8

Fig 7 shows a graph of pressure ratio against vibration velocity amplitude for the various bearings as considered in Table 1. The results show that the effect of vibration on the bearings is not exactly the same.

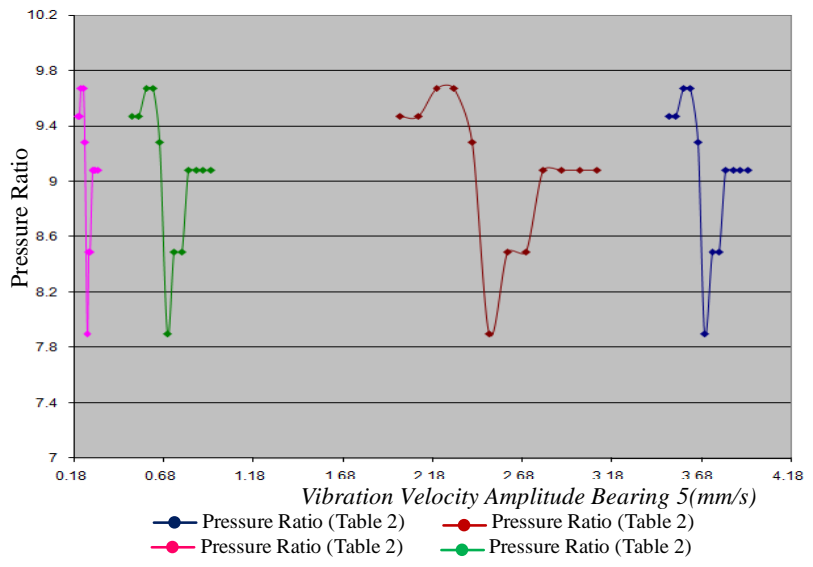

Fig.8 Pressure ratio against Vibration Velocity Amplitude Bearings 1,2,4, and 5 obtained from Equation 8

From the graph shown in figs 4 to 13 , it is observed that an increase in pressure ratio results to a corresponding increase in vibration velocity amplitude to some extent. Here, maximum vibration occurs at a pressure ratio of about 9.47 with a corresponding vibration velocity amplitude of $3.84 \mathrm{~mm} / \mathrm{s}$, 
$2.44 \mathrm{~mm} / \mathrm{s}, 1.26 \mathrm{~mm} / \mathrm{s}$ and $0.31 \mathrm{~mm} / \mathrm{s}$ respectively on bearings $1,2,4$ and 5 which is not advisable to run the engine at. This would also help to avoid shaft defects and even resonance on the engine.

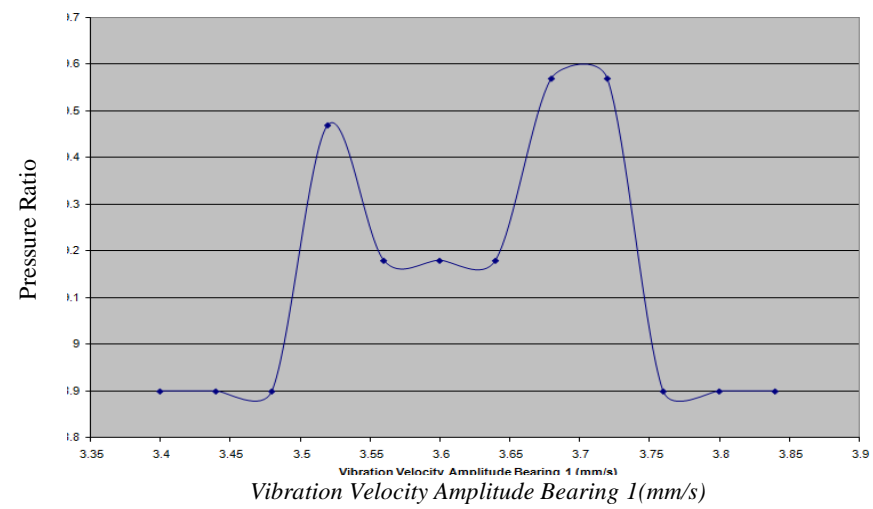

Fig.9 Pressure ratio against Vibration Velocity Amplitude Bearing 1

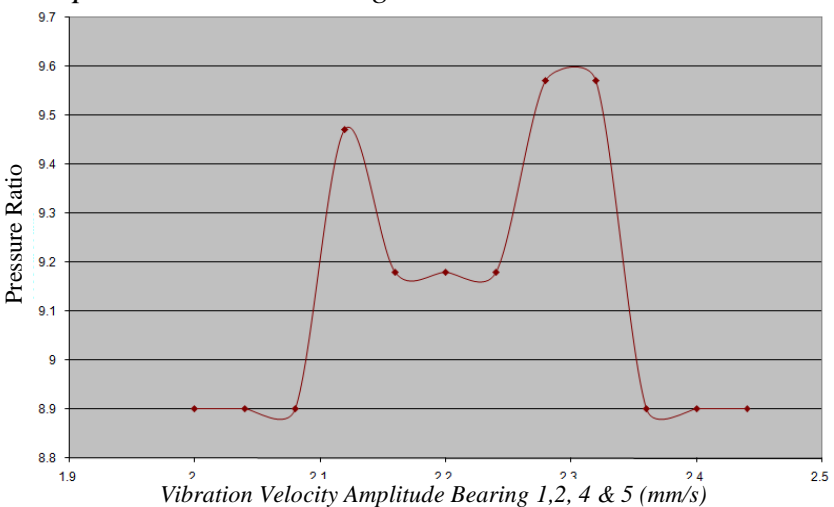

Fig.10 Pressure ratio against Vibration Velocity Amplitude Bearing 2

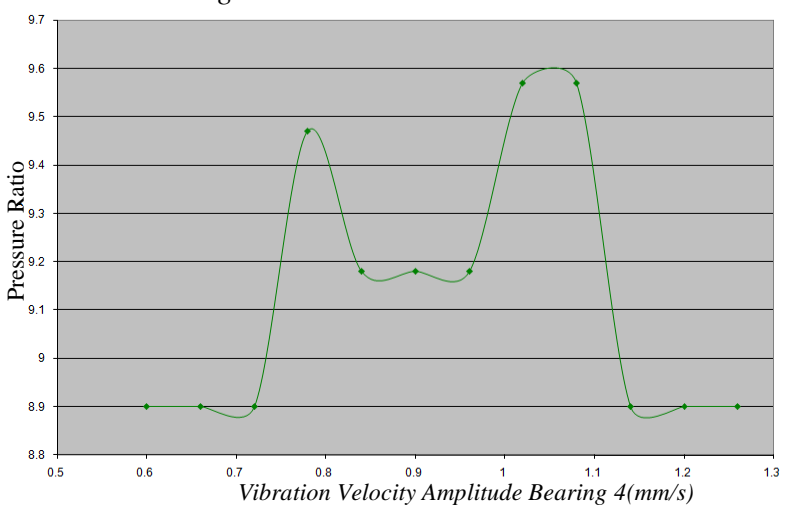

Fig.11 Pressure ratio against Vibration Velocity Amplitude Bearing 4

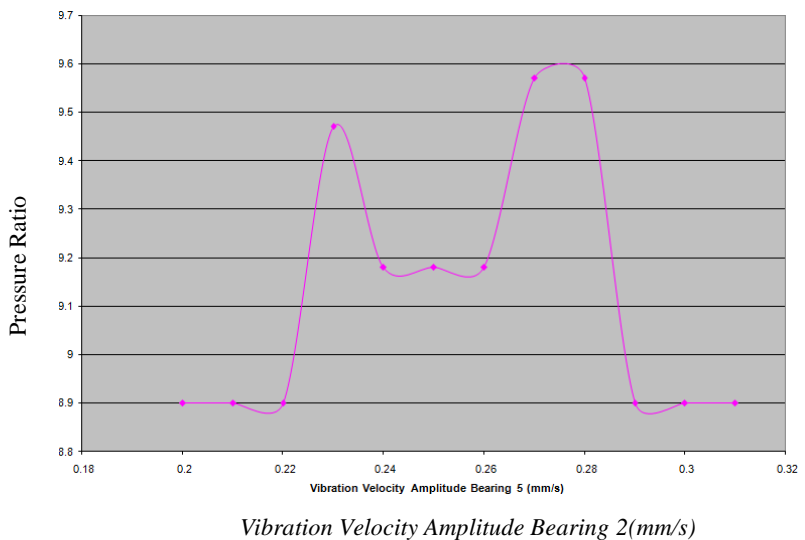

Fig.12 Pressure ratio against Vibration Velocity Amplitude Bearing 5

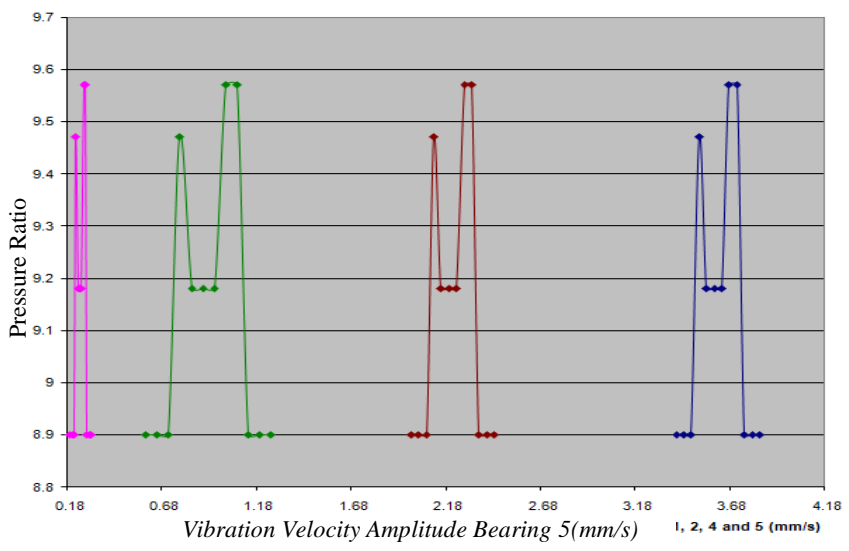

Fig. 13 Pressure ratio against vibration velocity amplitude of bearings 1,2,4, and 5

Figure 13 shows pressure ratio against their respective vibration velocity amplitudes. Table 3 contains a summary of the simulated results obtained for the test engine. The results show that the experimental and simulated values for pressure ratio and load correlate suitably. The deviation for the vibration amplitude is so much out of range because of the erratic and unpredictable nature of that parameter [3]. Hence a lot of attention needs to be given to take care of vibration signature and its average effects at design stage. 
IOSR Journal of Engineering

Apr. 2012, Vol. 2(4) pp: 544-554

Table 3: Summary of the simulated results obtained for the test engine

\begin{tabular}{|c|c|c|c|c|c|c|c|c|c|c|c|c|}
\hline & & & & & & & & & & & & \\
\hline & Experimental & Simulated & Deviation & Experimental & Simulated & Deviation & Experimental & Simulated & Deviation & Experimental & Simulated & Deviation \\
\hline $\begin{array}{l}\text { Velocity } \\
\text { Amplitude }\end{array}$ & 3.80 & 4.05 & $-6.17 \%$ & 1.87 & 2.05 & $-8.78 \%$ & 0.98 & 1.20 & $-18.33 \%$ & 0.127 & 0.28 & $-\overline{54.64 \%}$ \\
\hline Pressure & 8.72 & 9.50 & $-8.21 \%$ & 8.72 & 9.5 & $-8.21 \%$ & 8.72 & 9.50 & $-8.21 \%$ & 8.72 & 9.50 & $-8.21 \%$ \\
\hline Load & 55.5 & 58.9 & $-5.77 \%$ & 55.5 & 59.0 & $-5.93 \%$ & 55.5 & 58.9 & $-5.77 \%$ & 55.5 & 59.5 & $-6.72 \%$ \\
\hline
\end{tabular}

\section{Program Result}

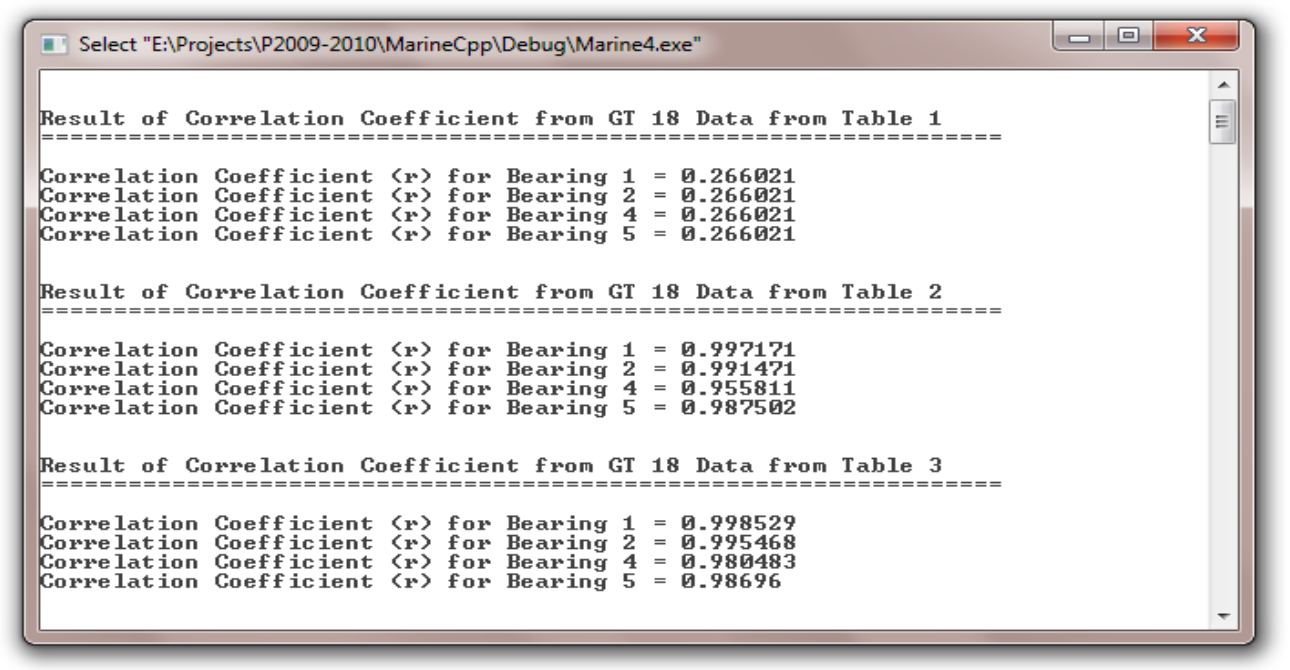

Fig. 14: Summary of program result in $\mathrm{VC}++$ for test engine

\section{Conclusions}

A research work has been carried out on correlation between pressure ratio and vibration amplitude of a marine GT. It is observed that the pressure ratio is a function of compressor discharge pressure and turbine inlet pressure. This is to complement the constant pressure process for which the design operation is based.

A step-by-step analysis of the plant parameters obtained is used to run computer simulations in $\mathrm{VC}++$ programming language. This is a determination of the correlation coefficient of the plant parameters as shown. The work also helped to confirm that the turbine side bearing of the GT plant carries much load and thus has high vibration amplitude.

\section{Recommendation}

It is recommended that a theory to suggest whether the relationship between two variables would either correlate positively or negatively should be developed for marine gas turbine engines anormaly detection..

\section{Acknowledgements}

The part played by the Management and Staff of Delta Thermal Station, Ughelli, Delta State, Nigeria in actualizing this work cannot be overemphasized. The authors also need to acknowledge Mr.Aghogho EDOH, Promise WILLIAM and kuvieEJABEFIO, students of the Department of Marine Engineering, Rivers State University of Science and Technology. They assisted relentlessly to collect the data, did most of the word processing associated with this work and assisted a great deal in the programming aspects of the work. We can never forget Mrs Q.C Ochomma of Department of Computer Management, University of Bolton, Greater Manchester, UK. In the initial typesetting, formatting and reformatting of the work. 


\section{References}

[1] R. Yadav, Steam and Gas Turbine and Power Plant, seventh revised ed., Central Publishing House, Allahabad, 2004.

[2] H. Cohen, G.F.C. Rogers, H.I.H. Saravanamutto, Gas Turbine Theory, fourth ed., Longman Group Limited, Great Britain, 1996.

[3] E.A. Ogbonnaya, Modeling Vibration-Based Faults in Rotor Shaft of a Gas Turbine, Ph.D Thesis, Department of Marine Engineering, Rivers State University of Science and Technology, Port Harcourt, 2004.

[4] J. Petek, P. Hamilton, Performance Monitoring for Gas Turbines "Gas Turbine Thermodynamics" J. Orbit, 25(1),(2005),65-68.

[5] S. Singh, Mechanical Vibration and Noise Control, first ed., Romesh Chander Khanna Publishers, Delhi, 2006.

[6] M.A. Tarbet, Gas Turbine Vibration Monitoring Systems, Magelian, (A Division of Woodward Communication), Inc., Ohio- U.S.A. [Online Series] Available: http://energy-tech.com /issues $/ \mathrm{html} /$ we 0006007,(2001), .html, 2002.

[7] D.D. Margineantu, T.G. Dietterich, Bootstrap Methods for the Cost-Sensitive Evaluation of Classifiers, Proceedings of the Seventeenth International Conference on Machine Learning, (2000).

[8] C.R. Davison,Laplace Correction of Confusion Matricese to Reduce Statitically Representative Confidence Intervals "Laplace Correction", J. Turbo Expo, ASME, (2010) 2.

[9] W. Jean, R. Ewen, and J. Cohen, Introductory Statistics for the Behavioural Sciences, Harcourt Brace Jovanovich, U.S.A., 2000.

[10] E.R. Walpole, Introduction to Statistics, Roanoke College, Macmillan, New York and Collier Macmillan, London, 2006.

[11] E.A. Ogbonnaya, K. Theophilus-Johnson, Use of Multi-Variable Mathematical Method for Effective Condition Monitoring of Gas Turbines, J.Turbo Expo, ASME (2010)1-9.

[12] E.A. Ogbonnaya, Statistical Correlation of Optimized Gas Turbine Fault Analysis. International Journal of $\begin{array}{llllll}\text { Engineering and Technology, } & \text { Vol. } & 2 & \text { No } & 2, & \text { (2012)163-172. }\end{array}$ 